\title{
Expression Profile of Wnt/ $\beta$-Catenin Signalling Molecules and the Wnt Antagonist Secreted Frizzled-Related Protein 4 in Apoptosis in Breast Cancer Tissue Micro-Arrays
}

\author{
A. Clare Berry ${ }^{1,2}$, Adrian Charles ${ }^{2}$, Nikolajs Zeps ${ }^{3}$, \\ Arun Dharmarajan ${ }^{1,5,{ }^{*}}$ \\ ${ }^{1}$ School of Anatomy, Physiology and Human Biology, UWA, Crawley, Australia \\ ${ }^{2}$ Department of Pediatric Pathology, Princess Margaret Hospital, Subiaco, Australia \\ ${ }^{3}$ St John of God Pathology, Subiaco, Australia \\ ${ }^{4}$ School of Biomedical Biomolecular and Chemical Sciences, UWA, Crawley, Australia \\ ${ }^{5}$ School of Biomedical Sciences, Curtin University
}

D. Mark Cregan ${ }^{4}$, Frank Arfuso ${ }^{1,5}$ and

\begin{abstract}
Wnt proteins are often up-regulated in cancer. The secreted frizzled-related proteins (sFRPs) can abrogate Wnt signalling and are involved in apoptosis. We investigated the expression of Wnt1, $\beta$-Catenin, and an antagonist, sFRP4, as well as apoptosis in breast cancer using tissue micro-arrays (TMAs) comprising 191 tissue cores. Results demonstrated stronger staining intensity for Wnt1 in tumour versus non-tumour samples $(p<0.05)$. Epithelial sFRP4 did not differ between invasive and non-invasive tissue; however, there was increased SFRP4 expression in the blood vessels and lymphocyte cells of tumour compared to non-tumour tissue. These data suggest Wnt involvement in determining the breast cancer phenotype and highlight a potential new role for sFRP4 as a diagnostic/prognostic marker.
\end{abstract}

Keywords: Wnt, Breast, cancer, tissue micro-arrays, secreted frizzled-related protein 4.

\section{INTRODUCTION}

Breast cancer is the most commonly diagnosed reproductive cancer in women and the second most frequent cause of cancer-related deaths. The Wnt pathway is known to be involved in normal development and cancer of the mammary gland [1-8]. Breast cancer can be diagnosed as a non-invasive type, for example ductal carcinoma in situ (DCIS) and lobular carcinoma in situ (LCIS), where the tumour tissue has not invaded past the ductal or lobular walls. Alternatively, breast cancer can be of the invasive type, where the tumour has invaded past the ductal and lobular walls, and infiltrates the mammary gland or surrounding organs and lymph nodes. These more invasive phenotypes of breast cancer are often associated with poorer prognosis.

The Wnt pathway has been shown to play a role in breast cancer; however, its role with tumour invasiveness is unknown. Wnt1 is a member of the Wnt pathway that is well defined as being up-regulated in breast cancer [9-11]. High $\beta$-Catenin levels have been detected in various cancers [12-14]. The association of

*Address correspondence to this author at the School of Biomedical Sciences, Faculty of Health Sciences, Curtin University and Curtin Health Innovation Research Institute (CHIRI) GPO Box U1987 Perth, 6845 Western Australia; Tel: + 6189266 4073; Fax: + 6189266 2342;

E-mail: a.dharmarajan@curtin.edu.au
Wnt1 and $\beta$-Catenin with tumour invasiveness has not been elucidated in breast cancer. SFRP4, an antagonist of the Wnt pathway and a recognised player in apoptosis, has also not been characterised with varying breast cancer invasiveness. Although sFRP4 has been shown to have an apoptotic role $[15,16]$, it has also been demonstrated to be up-regulated in cancers [12,17]. In addition, the establishment of sFRP4 expression in breast cancer of non-invasive and invasive phenotypes should also be investigated, along with apoptosis quantification.

Understanding the molecular characteristics that differ between non-invasive and invasive breast cancer will give insight into potential molecular targets for the treatment of the more invasive tumour type.

This study explores the Wnt signalling components in breast cancer by utilising tissue micro-arrays (TMAs). Additionally, the apoptotic status of the tissue was determined using TUNEL histochemistry.

\section{MATERIALS AND METHODS}

\section{Tissue Processing and Sectioning}

Human breast tissue microarray sections were obtained from the Western Australian Research Tissue Network (WARTN) from samples obtained from the Royal Perth Hospital (RPH) Pathology Department 
under ethics approvals granted by the RPH and Sir Charles Gairdner Hospital Human Research Ethics Committees. Samples were surgically removed at RPH between 1995 and 2001, fixed in 10\% buffered formalin (at physiologic $\mathrm{pH}$ ) for an average of 24 hours (this ranged between 6-48 hours depending on size of lesion and thickness of section) and embedded in paraffin. The sections included samples of normal adjacent breast tissue, and in situ and invasive carcinomas. For this study, a TMA section consisting of 191 tissue cores from 65 patients was used, which included 62 invasive tissue types, 75 non-invasive types (DCIS, LCIS), and 54 normal non-malignant adjacent tissue.

\section{Immunohistochemistry Staining}

Tissue sections (5 $\mu \mathrm{m}$ thickness) were obtained using a Leica R2135 microtome and placed on silanated Starfost $A$ adhesive treated slides. TMA slides were first dewaxed, rehydrated, and then antigen retrieval was performed using $10 \mathrm{mM}$ citrate buffer, $\mathrm{pH}$ 6.0 (sodium citrate tribasic dihydrate, Sigma-Aldrich). Endogenous peroxidases were blocked with 1\% hydrogen peroxide in TBS (Wnt1), 3\% hydrogen peroxide solution in TBS (sFRP4), or peroxidaseblocking solution from the DAKO REAL ${ }^{\mathrm{TM}}$ EnVision System Kit ( $\beta$-Catenin). Blocking was performed using $5 \%$ calf serum in $1 \times$ TBS (Wnt 1 ), $10 \%$ goat serum in 1 $x$ TBS with $0.01 \%$ Tween (sFRP4) or $2 \%$ calf serum in TBS ( $\beta$-Catenin) for 15 minutes. Primary antibodies (Mouse anti-active- $\beta$-Catenin, clone $8 \mathrm{E} 4, \quad 1: 400$ (Millipore); Rabbit anti sFRP4, 1:100 (Millipore); Rabbit anti-Wnt1 ab: 15251, 1:100 (AbCam)) were added to the slides and incubated at room temperature (RT) for one hour. For the secondary antibody incubation, a pre-optimised kit (Dako REAL ${ }^{\mathrm{TM}}$ EnVision Detection System, K5007, which works on both mouse and rabbit primary antibodies), was used for 30 minutes at RT. The sections were counterstained with Meyer's Haematoxylin then dehydrated, cleared and mounted using DePeX (Merck \& Co Inc) mounting medium.

\section{TUNEL Staining For DNA Fragmentation}

Terminal uridine deoxynucleotidyl transferase biotindUTP nick end labelling (TUNEL) staining is a common technique used for the identification of apoptotic cells, which was first described by Gavrieli [18]. TUNEL staining was performed on TMA slides to identify areas

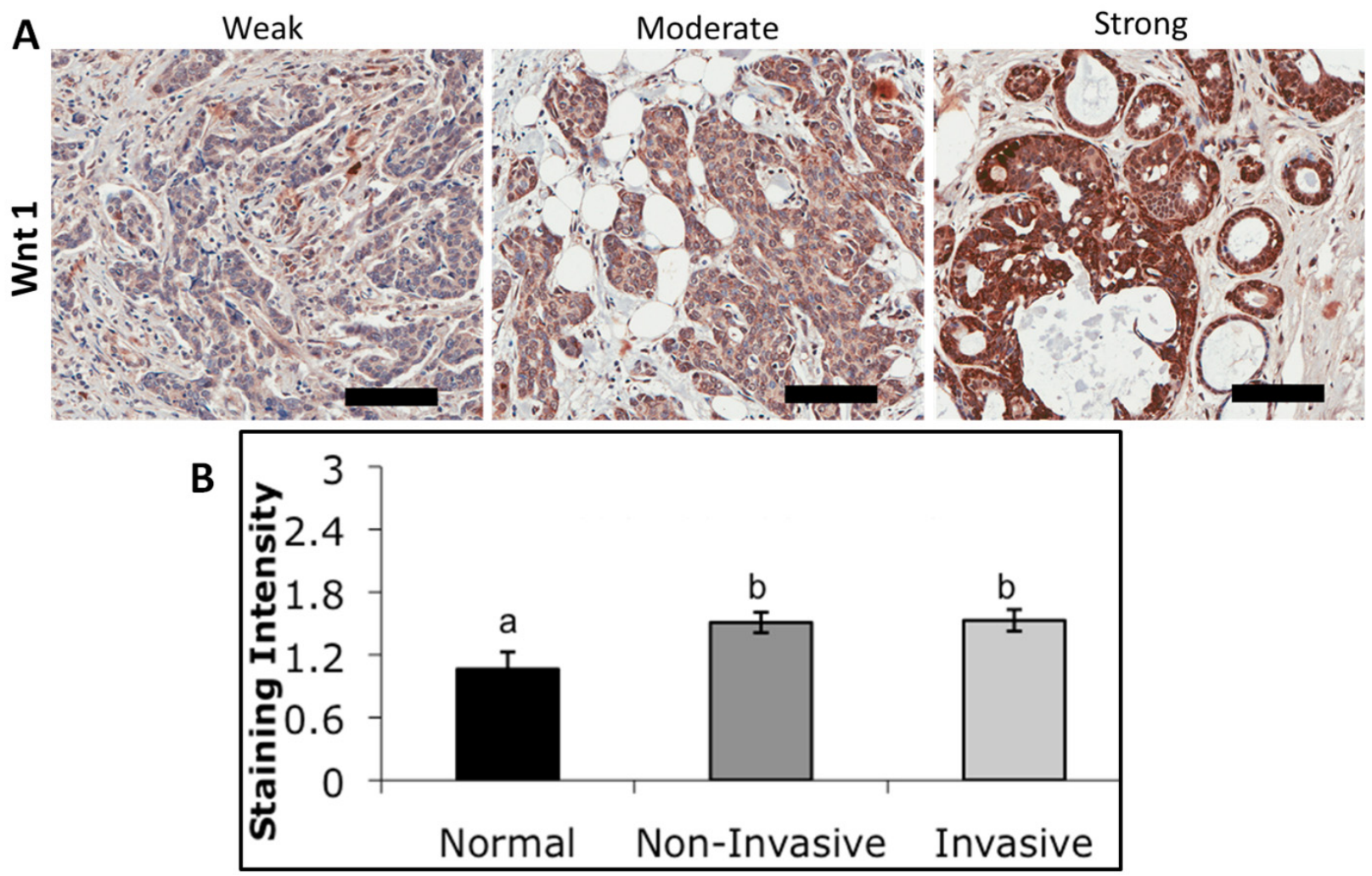

Figure 1: (A) Wnt1 staining intensity of epithelial cells in breast cancer TMAs showing weak, moderate, and strong expression. Staining was confined to the cell membrane and cytoplasmic regions. Scale bars $=100 \mu m$. (B) Relative staining intensities based on grading of expression for normal mammary, non-invasive, and invasive breast cancer from TMAs. Different superscripts represent a significant difference of $p<0.05$ between each superscript. 
undergoing DNA fragmentation using ApopTag ${ }^{\circledR}$ Plus Peroxidase In Situ Apoptosis Detection Kit (Millipore) following the manufacturer's recommendations. Positive TUNEL identification of cells consists of combining the identification of apoptotic morphology with positive $D A B$ staining, which is recommended in the manufacturer's instructions, as well as by others $[19,20]$.

\section{Analysis of TMA Slides}

Cores were graded as no expression (0), weak expression (1), moderate expression (2), or strong expression (3) by a clinical pathologist ( $\mathrm{Dr}$ Adrian Charles, School of Paediatrics and Child Health/School of Women's and Infants' Health, Faculty of Medicine, The University of Western Australia), depending on the intensity of staining. Total apoptotic cells were counted per core $\left(0.782 \mathrm{~mm}^{2}\right)$. Slides were scanned using an Aperio Scan Scope (Aperio Technologies) and photographs taken using Image Scope software. For comparisons, cores were divided into three groups: normal breast tissue, non-invasive breast tumour (including DCIS, LCIS), and invasive breast tumour.

\section{Statistical Analysis}

Data are represented as mean values \pm SEM. Differences between groups were analysed by an un- paired two-tailed $t$-test with equal variances using InStat 3 for Macintosh, Version 3.0b @1992-2003, and were considered statistically significant when $p<0.05$.

\section{RESULTS}

\section{Immunohistochemistry Staining of TMAs}

Immunohistochemistry (IHC) staining of TMAs showed that Wnt1 expression was mainly localised to the cytoplasmic regions of the epithelial cells but also demonstrated membranous expression (Figure 1A). The various staining intensities were examined between normal adjacent tissue, non-invasive tissue, and invasive tissue for Wnt1 (Figure 1B) and revealed that Wnt1 was significantly up-regulated in tumour tissue compared to normal adjacent tissue $(p<0.05)$, but did not change with invasive and non-invasive tissue types.

IHC for sFRP4 showed various expression levels in the cytoplasm of the epithelial cells, together with membranous expression (Figure 2A). Analysis of the staining intensity showed no significant difference between normal adjacent tissue, non-invasive tissue, and invasive tissue (Figure 2B).

$\beta$-Catenin demonstrated cytoplasmic membranous staining (Figure 3A) but, as seen with sFRP4, there

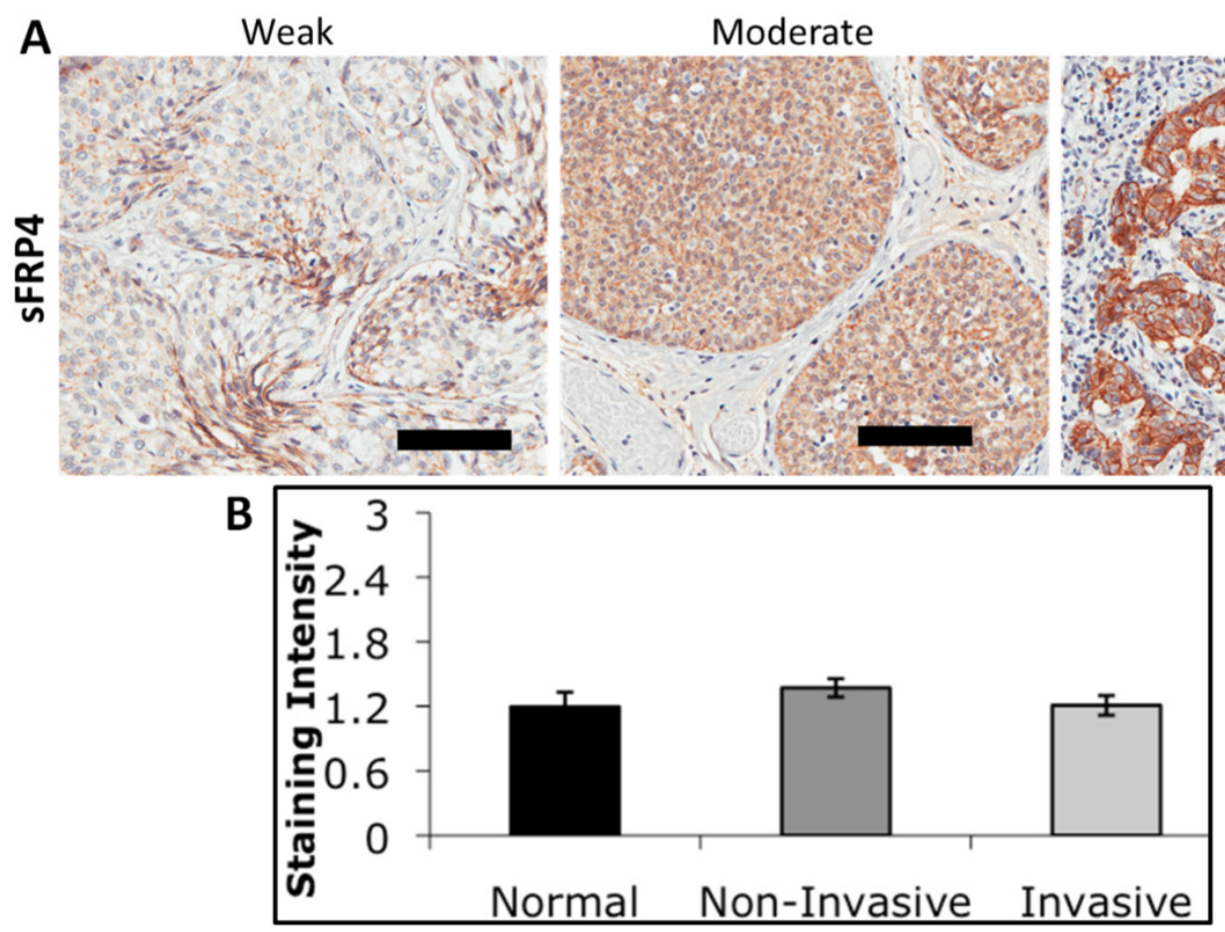

Figure 2: (A) sFRP4 staining intensity of epithelial cells in breast cancer TMAs showing weak, moderate, and strong expression in the cytoplasm and cell membrane of the epithelial cells. Scale bars $=100 \mu \mathrm{m}$. (B) Relative staining intensities based on grading of expression for normal mammary, non-invasive, and invasive breast cancer from TMAs. 


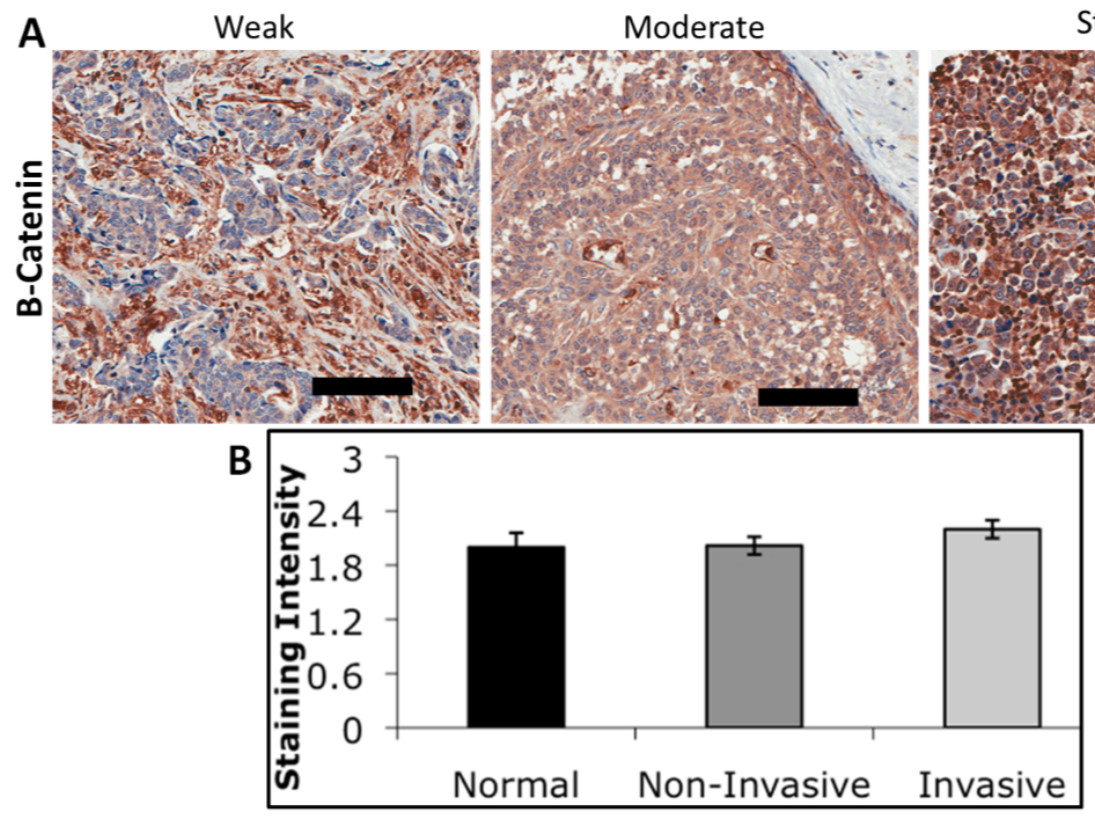

Figure 3: (A) $\beta$-Catenin staining intensity of epithelial cells in breast cancer TMAs showing weak, moderate, and strong expression. $\beta$-Catenin displayed cytoplasmic and membranous staining. Scale bars $=100 \mu m(B)$ Relative staining intensities based on grading of expression for normal mammary, non-invasive, and invasive breast cancer from TMAs.

was no significant difference between normal adjacent tissue, non-invasive tissue, and invasive tissue (Figure 3B). However, there was no significant correlation of sFRP4 staining with Wnt1 and $\beta$-Catenin in this study (data not shown).
Surprisingly, sFRP4 IHC of blood vessels revealed staining of the endothelial cells (Figure 4A). Analysis of the staining intensity revealed a significant increase in staining intensity from normal to tumour tissue $(p<0.05)$ (Figure 4B).

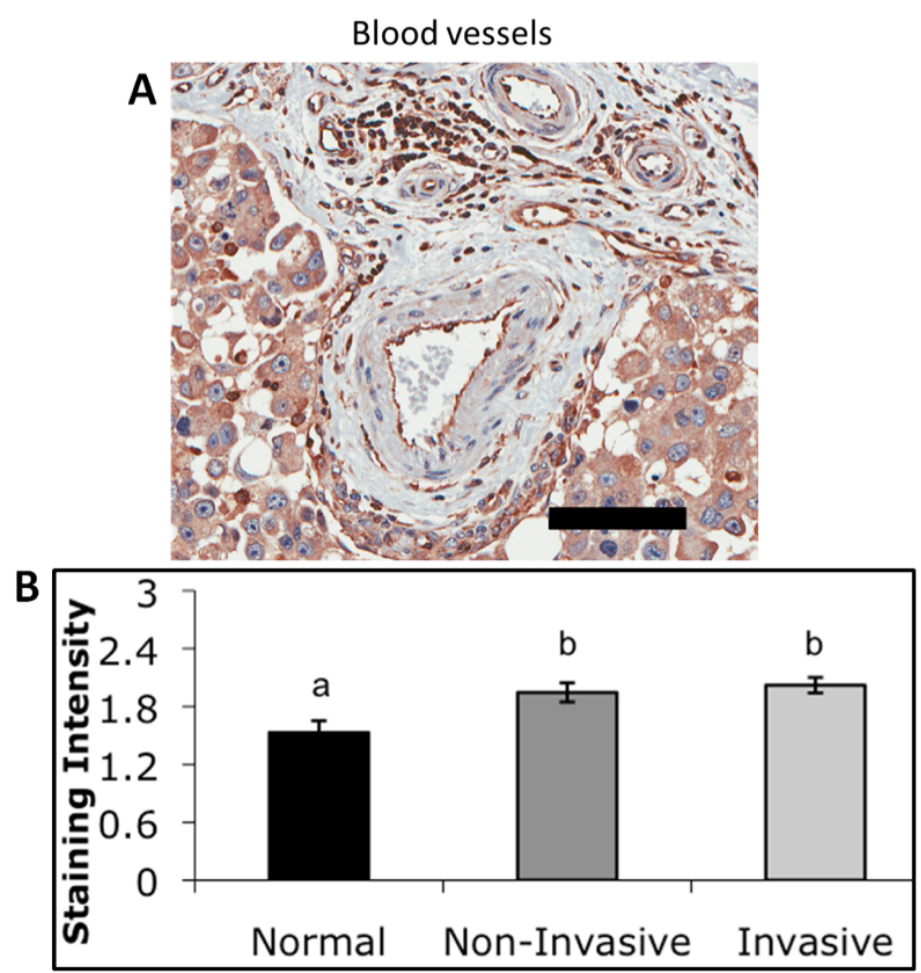

Figure 4: (A) sFRP4 expression was demonstrated in the blood vessels and endothelial cells (K, arrows) of breast cancer tissue. Scale bar $=100 \mu \mathrm{m}$. (B) Relative staining intensities based on grading of expression for normal mammary, non-invasive, and invasive breast cancer from TMAs. Different superscripts represent a significant difference of $p<0.05$ between each superscript. 


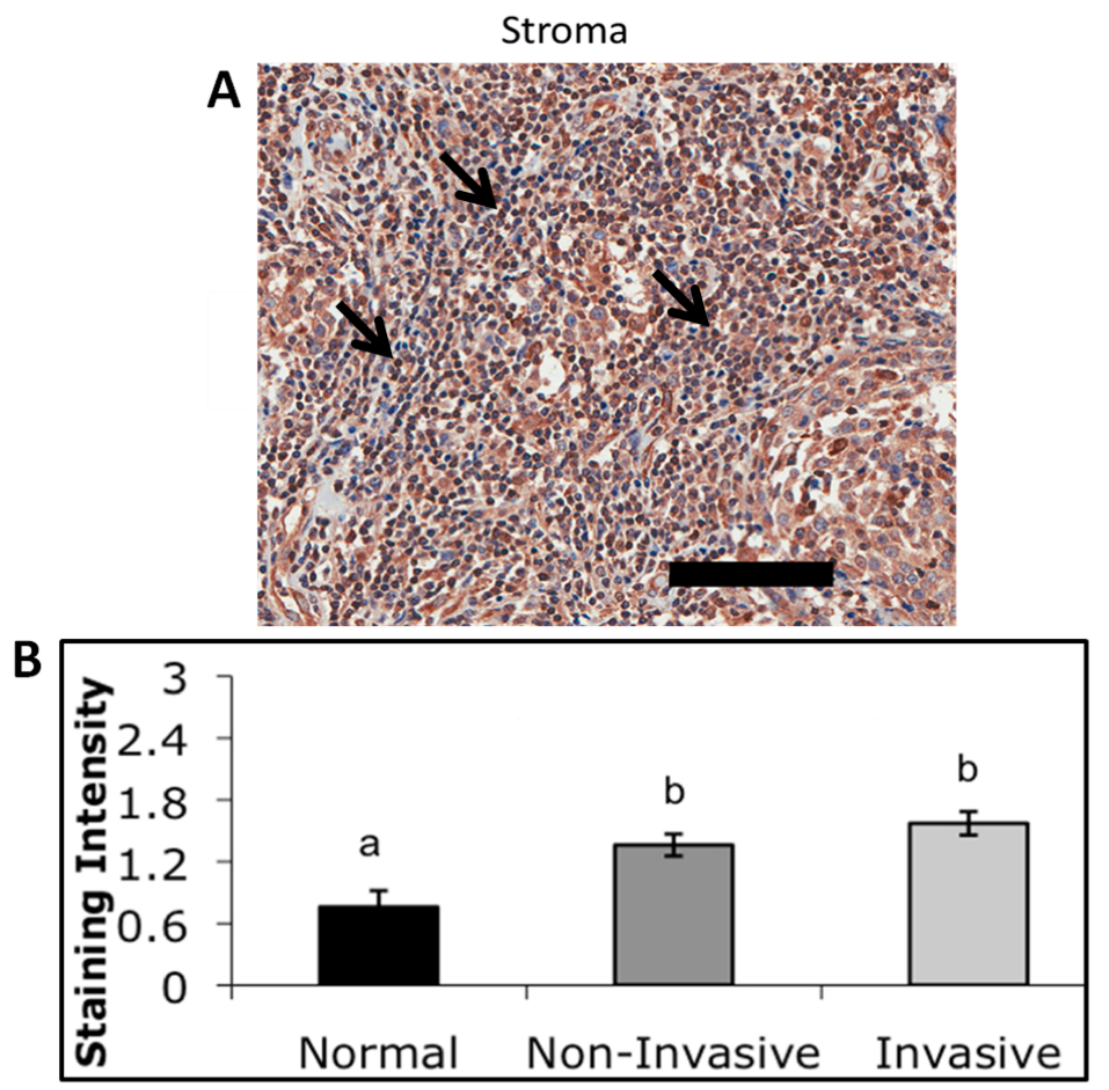

Figure 5: (A) sFRP4 expression was also identified in stromal areas, including lymphocytes (arrows). Scale bar = 100 $\mu m$. $($ B) Relative staining intensities based on grading of expression for normal mammary, non-invasive, and invasive breast cancer from TMAs. Different superscripts represent a significant difference of $p<0.05$ between each superscript.

Of particular interest was the evidence of sFRP4 staining in the stromal regions, including lymphocytes (Figure 5A), which also revealed a significant increase in staining intensity between normal and tumour tissues $(p<0.05)$ (Figure 5B).

\section{TUNEL Staining of TMAs}

TUNEL staining demonstrated that there are significantly more apoptotic cells per core in tumour samples compared to normal breast tissue (Figure 6A), and there were also significantly more apoptotic cells per core in invasive tissue compared to non-invasive breast tissue (Figure 6B).

\section{DISCUSSION}

This study sought to compare and correlate the relative expression of Wnt1, $\beta$-Catenin, and SFRP4 in breast cancer TMAs, as well as comparing the expression to the number of apoptotic cells measured by TUNEL. Although others have investigated Wnt1 and $\beta$-Catenin in breast cancer previously [21], this study incorporated correlations between the expression of Wnt1, $\beta$-Catenin, and SFRP4, and additionally looked at comparisons among normal adjacent breast tissue and non-invasive and invasive breast tumour types.

We found that Wnt1 staining in the breast cancer TMAs showed typical cytoplasmic staining in both normal and tumour tissue, together with membranous staining. It is well established that Wnt1 is involved in breast cancer [9-11]; however, this study has revealed that Wnt1 expression does not differ with breast cancer invasiveness, showing that Wnt1 plays a role in a breast tumour phenotype but not with a more advanced disease state, which is in agreement with Karim et al. [21] who found that, while cytoplasmic Wnt1 expression increased with increasing tumour grade, it was not a statistically significant difference. Indeed, a more recent study [22] reported that Wnt1 is only involved in the initial phases of breast cancer development, where it supports differentiation and apoptosis of the tumour cells.

$\beta$-Catenin is known to be involved in normal mammary gland function [7], and is typically overexpressed in cancers [14]. $\beta$-Catenin expression was detected in both normal and cancerous tissue, and 


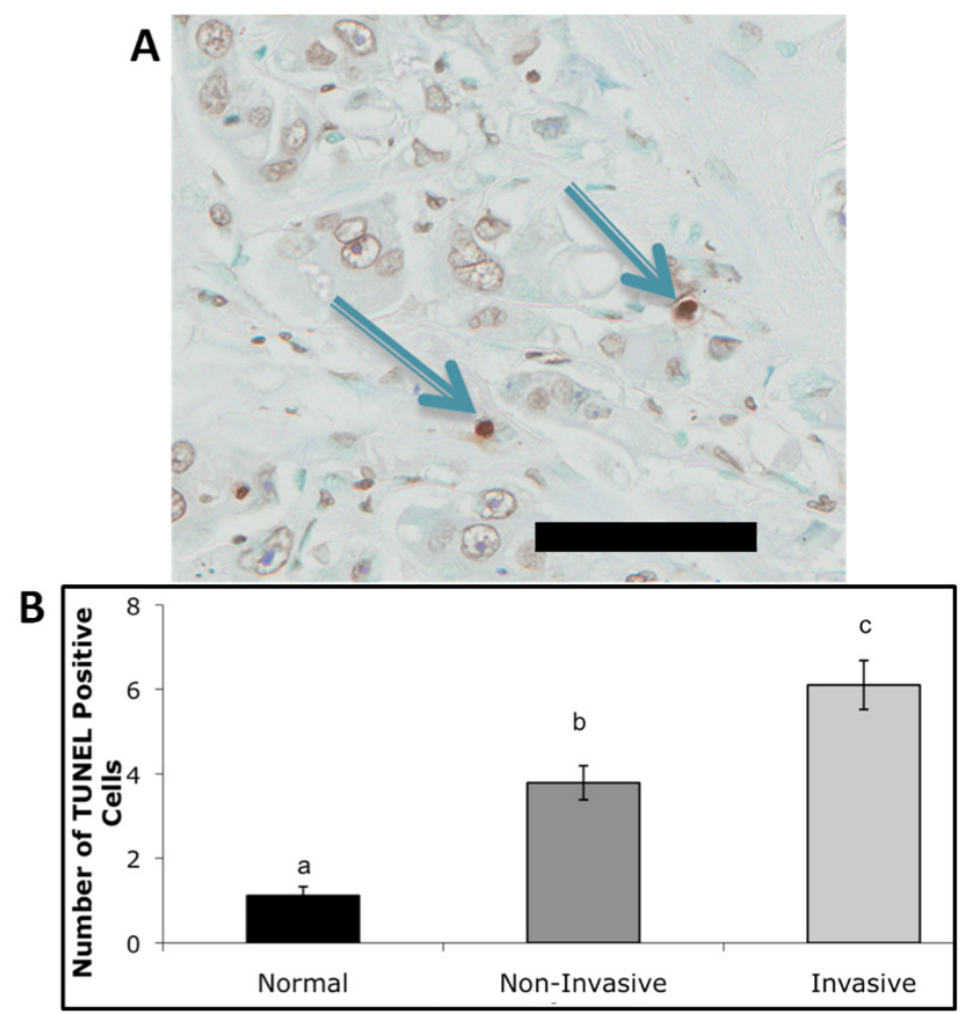

Figure 6: TUNEL staining in invasive breast cancer TMAs (A), where apoptotic cells stain brown (arrow). Comparisons for the total number of apoptotic cells identified per core for normal mammary, non-invasive, and invasive breast cancer (B). Different superscripts represent a significant difference of $p<0.05$ between each superscript. Scale bar $=80 \mu \mathrm{m}$.

displayed cytoplasmic membranous staining, which has been shown by others in prostate and colorectal cancer cells $[12,23]$. Loss of $\beta$-Catenin expression on the cytoplasmic membrane has been previously associated with aggressive breast tumours [24]. Contrary to this, exclusive membranous staining of $\beta$-Catenin represented poorer prognosis of endometrioid carcinomas [13]. The role of $\beta$-Catenin here remains unclear and may be attributed to other roles for $\beta$ Catenin such as cell adhesion. The Catenin association with Cadherins such as E-Cadherin is critical for cell adhesion, and any changes in the Catenin molecules can lead to tumour aggression [25].

After examining the expression of Wnt1, we examined the expression of the Wnt antagonist sFRP4, which is known to have a pro-apoptotic role $[15,16]$; however, it has been revealed to be up-regulated in colorectal cancer [12] and malignant mesothelioma [17]. In this current study, sFRP4 expression was localised to the cytoplasmic and membranous regions of epithelial cells.

Additionally, this is the first known study identifying sFRP4 staining within blood vessels and stromal regions of breast cancer. Recently SFRP2 was shown to be expressed in vascular cells of breast cancer [26]. Current studies have shown sFRP4 to have an antiangiogenic role [27]. The increased SFRP4 expression seen here in blood vessels of tumour tissue may reflect this anti-angiogenic role.

It has been reviewed that the involvement of the immune cells in tumours can be either tumour promoting or tumour rejecting; where natural killer cells can be recruited to restrain tumour growth, while contrarily, tumour-associated macrophages can secrete growth factors and cytokines that can promote tumour growth [28, 29]. Recently, there has been a positive association found with tumour infiltrating macrophages and vascular endothelial growth factor (VEGF) secretion that assists in tumour angiogenesis [30], suggesting an association between the immune cells in the stroma and blood vessel formation. Our observation of sFRP4 expression in the immune cells of the stromal regions of breast cancer tissue and blood vessels further confirms that sFRP4 is playing a role inhibiting angiogenesis and tumour growth. Taking into account the established anti-angiogenic abilities of sFRP4 described above, it is postulated that the role of sFRP4 is compensatory and tumour inhibiting. Indeed, we have recently reported that SFRP4 expression is 
correlated with chemoresistance in ovarian cell lines and, more importantly, our data obtained from patient TMAs indicate that sFRP4 expression may act as a predictive marker for tumour aggressiveness [31].

Others have shown that there is a relationship between SFRP4 and $\beta$-Catenin in colorectal cancer [12]. Interestingly, increased SFRP4 expression has also been associated with increased membranous $\beta$ Catenin expression [32]. However, in this study there was no correlation between any of the Wnt pathway components analysed, perhaps reflecting that correlations may be tissue specific or that other Wnt components not tested here have a more significant correlation with these members.

We also investigated whether there was any correlation between the breast tumour type and subsequent Wnt pathway component expression. These results confirm that Wnt 1 is up-regulated in breast cancer, and that it is not involved with a more invasive breast tumour type; both findings confirming those of previous studies [9-11,21,22]. Epithelial $\beta$ Catenin and sFRP4 revealed no significant difference between tumour types and also between normal and tumour tissue. SFRP4 in stromal regions and blood vessels demonstrated significantly stronger expression in tumour tissue compared to normal tissue but did not show any difference between invasive and noninvasive tumour types. Similarly, this is the first study to demonstrate that stromal and blood vessel expression of SFRP4 is increased in breast cancer compared to normal breast tissue.

A higher number of TUNEL-positive apoptotic cells was observed in breast tumour tissue samples compared to normal types. These data confirm that invasive breast tumour tissue has a higher proportion of apoptotic cells compared to non-invasive and normal breast tissue. However, it needs to be considered that more invasive breast tumours will have high levels of cell division occurring and thus will also have higher apoptotic numbers.

This study confirms that the Wnt pathway is involved in the development of the breast cancer phenotype but may not be associated with a more invasive breast tumour type. Specifically, Wnt1 expression is involved with tumour physiology, and uniquely, sFRP4 staining of blood vessels and stromal regions is also stronger in breast tumour tissue. The latter finding is novel, and may present SFRP4 as a new potential therapeutic marker that requires further investigation.

\section{ACKNOWLEDGEMENTS}

Ms Lisa Spalding (WARTN) generously prepared cut sections of the breast TMA blocks and scanned the TMA slides. CB was supported by Medela AG., Switzerland. AD was supported by Curtin University School of Biomedical Sciences Strategic Research Funds and Cancer Council WA. The authors also thank Dr Adrian Charles, School of Paediatrics and Child Health/School of Women's and Infants' Health, Faculty of Medicine, The University of Western Australia, for grading of the TMA cores.

\section{CONFLICT OF INTEREST}

The authors declare that there is no conflict of interest regarding the publication of this paper.

\section{REFERENCES}

[1] Ayyanan A, Civenni G, Ciarloni L, Morel C, Mueller N, Lefort $\mathrm{K}$, et al. Increased Wnt signaling triggers oncogenic conversion of human breast epithelial cells by a Notchdependent mechanism. Proceedings of the National Academy of Sciences of the United States of America 2006; 103: $3799-804$

http://dx.doi.org/10.1073/pnas.0600065103

[2] Benhaj K, Akcali KC, Ozturk M. Redundant expression of canonical Wnt ligands in human breast cancer cell lines. Oncology reports 2006; 15: 701-7.

[3] Bui TD, Rankin J, Smith K, Huguet EL, Ruben S, Strachan T, et al. A novel human Wnt gene, WNT10B, maps to $12 \mathrm{q} 13$ and is expressed in human breast carcinomas. Oncogene 1997; 14: 1249-53.

http://dx.doi.org/10.1038/sj.onc.1200936

[4] Huguet EL, McMahon JA, McMahon AP, Bicknell R, Harris AL. Differential expression of human Wnt genes 2, 3, 4, and $7 \mathrm{~B}$ in human breast cell lines and normal and disease states of human breast tissue. Cancer research 1994; 54: 2615-21.

[5] Lane TF, Leder P. Wnt-10b directs hypermorphic development and transformation in mammary glands of male and female mice. Oncogene 1997; 15: 2133-44. http://dx.doi.org/10.1038/sj.onc.1201593

[6] Liu X, Robinson GW, Hennighausen L. Activation of Stat5a and Stat $5 \mathrm{~b}$ by tyrosine phosphorylation is tightly linked to mammary gland differentiation. Molecular endocrinology 1996; 10: 1496-506.

[7] Tepera SB, McCrea PD, Rosen JM. A beta-catenin surviva signal is required for normal lobular development in the mammary gland. Journal of cell science 2003; 116: 1137-49. http://dx.doi.org/10.1242/jcs.00334

[8] Chu EY, Hens J, Andl T, Kairo A, Yamaguchi TP, Brisken C et al. Canonical WNT signaling promotes mammary placode development and is essential for initiation of mammary gland morphogenesis. Development 2004; 131: 4819-29. http://dx.doi.org/10.1242/dev.01347

[9] Wong SC, Lo SF, Lee KC, Yam JW, Chan JK, Wendy Hsiao WL. Expression of frizzled-related protein and Wnt-signalling molecules in invasive human breast tumours. The Journal of pathology 2002; 196: 145-53. http://dx.doi.org/10.1002/path.1035

[10] Katoh M. Expression and regulation of WNT1 in human cancer: up-regulation of WNT1 by beta-estradiol in MCF-7 cells. International journal of oncology 2003; 22: 209-12. 
[11] Milovanovic T, Planutis K, Nguyen A, Marsh JL, Lin F, Hope $\mathrm{C}$, et al. Expression of Wnt genes and frizzled 1 and 2 receptors in normal breast epithelium and infiltrating breast carcinoma. International journal of oncology 2004; 25: 133742.

[12] Feng Han Q, Zhao W, Bentel J, Shearwood AM, Zeps N, Joseph D, et al. Expression of SFRP-4 and beta-catenin in human colorectal carcinoma. Cancer letters 2006; 231: 12937.

\section{http://dx.doi.org/10.1016/j.canlet.2005.01.026}

[13] Gamallo C, Palacios J, Moreno G, Calvo de Mora J, Suarez A, Armas A. beta-catenin expression pattern in stage I and II ovarian carcinomas: relationship with beta-catenin gene mutations, clinicopathological features, and clinical outcome. The American journal of pathology 1999; 155: 527-36. http://dx.doi.org/10.1016/S0002-9440(10)65148-6

[14] Teuliere J, Faraldo MM, Deugnier MA, Shtutman M, BenZe'ev A, Thiery JP, et al. Targeted activation of beta-catenin signaling in basal mammary epithelial cells affects mammary development and leads to hyperplasia. Development 2005; 132: 267-77.

http://dx.doi.org/10.1242/dev.01583

[15] Drake JM, Friis RR, Dharmarajan AM. The role of sFRP4, a secreted frizzled-related protein, in ovulation. Apoptosis: an international journal on programmed cell death 2003; 8: 38997.

http://dx.doi.org/10.1023/A:1024181203729

[16] Maganga R, Giles N, Adcroft K, Unni A, Keeney D, Wood F, et al. Secreted Frizzled related protein-4 (sFRP4) promotes epidermal differentiation and apoptosis. Biochemical and biophysical research communications 2008; 377: 606-11. http://dx.doi.org/10.1016/j.bbrc.2008.10.050

[17] Fox S, Dharmarajan A. WNT signaling in malignant mesothelioma. Frontiers in bioscience: a journal and virtual library 2006; 11: 2106-12. http://dx.doi.org/10.2741/1953

[18] Gavrieli $Y$, Sherman $Y$, Ben-Sasson SA. Identification of programmed cell death in situ via specific labeling of nuclear DNA fragmentation. The Journal of Cell Biology 1992; 119: 493-501.

http://dx.doi.org/10.1083/jcb.119.3.493

[19] Jerome KR, Vallan C, Jaggi R. The tunel assay in the diagnosis of graft-versus-host disease: caveats for interpretation. Pathology 2000; 32: 186-90.

[20] Labat-Moleur F, Guillermet C, Lorimier P, Robert C, Lantuejoul S, Brambilla E, et al. TUNEL apoptotic cell detection in tissue sections: critical evaluation and improvement. The journal of histochemistry and cytochemistry: official journal of the Histochemistry Society 1998; 46: 327-34. http://dx.doi.org/10.1177/002215549804600306

[21] Karim RZ, Gerega SK, Yang YH, Horvath L, Spillane A, Carmalt $\mathrm{H}$, et al. Proteins from the Wnt pathway are involved in the pathogenesis and progression of mammary phyllodes tumours. Journal of clinical pathology 2009; 62: 1016-20. http://dx.doi.org/10.1136/jcp.2009.066977
[22] Mylona E, Vamvakaris I, Giannopoulou I, Theohari I, Papadimitriou C, Keramopoulos A, et al. An immunohistochemical evaluation of the proteins Wnt1 and glycogen synthase kinase (GSK)-3beta in invasive breast carcinomas. Histopathology 2013; 62: 899-907. http://dx.doi.org/10.1111/his.12095

[23] Hovey RC, Trott JF, Vonderhaar BK. Establishing a framework for the functional mammary gland: from endocrinology to morphology. Journal of mammary gland biology and neoplasia 2002; 7: 17-38. http://dx.doi.org/10.1023/A:1015766322258

[24] Prasad CP, Gupta SD, Rath G, Ralhan R. Wnt signaling pathway in invasive ductal carcinoma of the breast: relationship between beta-catenin, dishevelled and cyclin D1 expression. Oncology 2007; 73: 112-7. http://dx.doi.org/10.1159/000120999

[25] Okegawa T, Pong RC, Li Y, Hsieh JT. The role of cell adhesion molecule in cancer progression and its application in cancer therapy. Acta biochimica Polonica 2004; 51: 44557.

[26] Bhati R, Patterson C, Livasy CA, Fan C, Ketelsen D, Hu Z, et al. Molecular characterization of human breast tumor vascular cells. The American journal of pathology 2008; 172 : 1381-90. http://dx.doi.org/10.2353/ajpath.2008.070988

[27] Muley A, Majumder S, Kolluru GK, Parkinson S, Viola H, Hool L, et al. Secreted frizzled-related protein 4: an angiogenesis inhibitor. The American journal of pathology 2010; 176: 1505-16.

http://dx.doi.org/10.2353/ajpath.2010.090465

[28] Balkwill F, Mantovani A. Inflammation and cancer: back to Virchow? Lancet 2001; 357: 539-45. http://dx.doi.org/10.1016/S0140-6736(00)04046-0

[29] DeNardo DG, Coussens LM. Inflammation and breast cancer. Balancing immune response: crosstalk between adaptive and innate immune cells during breast cancer progression. Breast cancer research: BCR 2007; 9: 212. http://dx.doi.org/10.1186/bcr1746

[30] Barbera-Guillem E, Nyhus JK, Wolford CC, Friece CR, Sampsel JW. Vascular endothelial growth factor secretion by tumor-infiltrating macrophages essentially supports tumor angiogenesis, and $\operatorname{lgG}$ immune complexes potentiate the process. Cancer research 2002; 62: 7042-9.

[31] Saran U, Arfuso F, Zeps N, Dharmarajan A. Secreted frizzled-related protein 4 expression is positively associated with responsiveness to cisplatin of ovarian cancer cell lines in vitro and with lower tumour grade in mucinous ovarian cancers. BMC cell biology 2012; 13: 25. http://dx.doi.org/10.1186/1471-2121-13-25

[32] Horvath LG, Lelliott JE, Kench JG, Lee CS, Williams ED, Saunders DN, et al. Secreted frizzled-related protein 4 inhibits proliferation and metastatic potential in prostate cancer. The Prostate 2007; 67: 1081-90.

http://dx.doi.org/10.1002/pros.20607 